\title{
Trypanosoma cruzi in the Anal Glands of Urban Opossums. I- Isolation and Experimental Infections
}

\author{
S Urdaneta-Morales ${ }^{+}$, I Nironi \\ Sección de Parasitología, Instituto de Zoología Tropical, Facultad de Ciencias, Universidad Central de \\ Venezuela, Apartado 47058, Caracas 1041-A, Venezuela
}

\begin{abstract}
Opossums (Didelphis marsupialis) captured in intensely urbanized areas of the city of Caracas, Venezuela, were found infected with Trypanosoma cruzi. The developmental cycle of trypomastigoteepimastigote-metacyclic infective trypomastigote, usually occurring in the intestine of the triatomine vector, was taking place in the anal odoriferous glands of the opossums. Material from the glands, inoculated in young, healthy opossums and white mice by different routes, subcutaneously, intraperitoneally, orally, and into the eye, induced T. cruzi infections in all animals. Parasitemia, invasion of cardiac and skeletal muscle, and intracellular multiplication of amastigotes were observed. Inoculation of metacyclics from anal glands, cultured in LIT medium, gave equivalent results. All opossums survived; all mice died. Excreta of opossums may thus transmit Chagas' disease by contamination, even in urban areas where insect vectors are not present.
\end{abstract}

Key words: Trypanosoma cruzi - opossum - anal glands - Didelphis marsupialis - urban American trypanosomiasis - Venezuela

In 1986, Deane et al. have shown that the entire developmental cycle of Trypanosoma cruzi (epimastigote-trypomastigote-metacyclic trypomastigote) may take place within the odoriferous anal glands of the opossum Didelphis marsupialis, thus potentially bypassing the development in the insect vector.

In our current investigation of $T$. cruzi mammalian reservoirs in the intensely urbanized areas of the valley of Caracas, Venezuela, we have found high indices of infection in D. marsupialis (Herrera \& Urdaneta-Morales 1992). The present paper describes the presence of all stages of $T$. cruzi in the content of the anal glands of these opossums, as well as the results of experimental infections performed in opossums and mice.

\section{MATERIALS AND METHODS}

Natural infections - Twelve D. marsupialis were captured using wire mesh traps baited with fruit and placed near human dwellings in Los Chorros, La Trinidad, and Colinas de Bello Monte, all representing urbanized areas of the valley of Caracas (Pifano 1986).

\footnotetext{
This study was funded by the Consejo Nacional de Investigaciones Científicas y Tecnológicas (CONICIT), grant No. S1-2444.

${ }^{+}$Corresponding author. Fax: 58-2-752.5897

Received 16 February 1995

Accepted 9 January 1996
}

Examinations - Fresh tail blood from the opossums was microscopically examined at $400 \mathrm{X}$, and Giemsa-stained thin films were also made to detect parasitemias. Each animal was examined by xenodiagnosis, using 12 third stage nymphs of Rhodnius prolixus, bred at the laboratory. After three weeks, feces from these bugs, mixed (1:1) with $0.85 \% \mathrm{NaCl}$, were microscopically examined. Those samples found positive for flagellates were used to make Giemsa-stained thin films, as well as to inoculate subcutaneously $(\mathrm{s} / \mathrm{c})$ one adult opossum already known to be negative for $T$. cruzi, and 2 NMRI mice. Hemolymph, obtained after cutting the tarsus, was also microscopically examined (D’Alessandro 1976).

Opossums were anesthetized with $0.05 \mathrm{mg} / \mathrm{kg}$ sodium Nembutal (Merck $\mathrm{C}_{11} \mathrm{H}_{17} \mathrm{~N}_{2} \mathrm{O}_{3} \mathrm{Na}$ ). The contents of the anal glands were obtained by manual compression (Deane et al. 1986), and diluted in saline to make both fresh preparations and Giemsa-stained thin films.

Glandular flagellates aseptically obtained from one animal were cultured in $2 \mathrm{ml}$ of LIT medium (liver infusion tryptose) plus $0.1 \mathrm{mg} / \mathrm{ml} \mathrm{Gentamycin,}$ at $24^{\circ} \mathrm{C}$. Subcultures were made weekly.

Experimental infections - Six juvenile opussums (mean wt $350 \mathrm{~g}$ ) were inoculated intraperitoneally (i/p) or s/c with 200 metacyclics/g (Jansen et al. 1991), quantified according to Brener (1962) from the glandular content of a naturally infected opossum. These animals were obtained from the pouches of females which, together with their litters, had been found negative for $T$. cruzi 
by both blood examination and xenodiagnosis. The equivalent inoculum was administered orally to an adult opossum $(2.5 \mathrm{~kg})$, negative for $T$. cruzi.

Nine juvenile opossums (mean wt $350 \mathrm{~g}$ ) were inoculated with metacyclic trypanosomes from cultures at the same dose; three routes were used - s/c, orally, and into the eye. Three animals were allotted to each route.

For each of these experiments, parallel groups of three mice (mean wt $7 \mathrm{~g}$ ) were inoculated in the same way.

Parasitemias of the experimentally infected animals were assessed daily for mice, and every two days for opossums, from the third day of inoculation onwards, until parasitemia disappeared, or the animal died.

The anal glands of the experimentally infected opossums were examined weekly; samples of the gland content showing parasites were inoculated $\mathrm{s} / \mathrm{c}$ into mice, which were examined as above.

Opossums and mice were sacrificed by anesthetic overdose, and cervical dislocation, respectively. Tissue samples from heart, skeletal muscle, liver, spleen, small intestine, large intestine, dia- phragm, lung, and anal glands were fixed in $10 \%$ formalin, imbedded in paraffin, cut into $5 \mu$ sections, and stained with hematoxylin-eosin. Presence of parasites was microscopically (1000 X) checked by two observers working independently.

Microphotographs of the glandular flagellates, as well as of the intracellular parasites, were made with a Nikon Microflex HFX-35, on Ilford Pan-F film.

\section{RESULTS}

A total of 12 D. marsupialis were captured, and four from Colinas de Bello Monte were infected with T. (Schizotrypanum) cruzi Chagas, 1909. Identification was based on the morphology of the flagellates from blood, from the glandular material and its cultures, and from bug feces (Barretto 1979, WHO 1986). Also, in natural and experimental infections of opossums, and experimental infections of mice, the typical pleomorphism of $T$. cruzi (Urdaneta-Morales 1983) was observed, with a predominance of stout forms. The feces of bugs used for xenodiagnosis infected the mice and the opossum, when inoculated s/c.

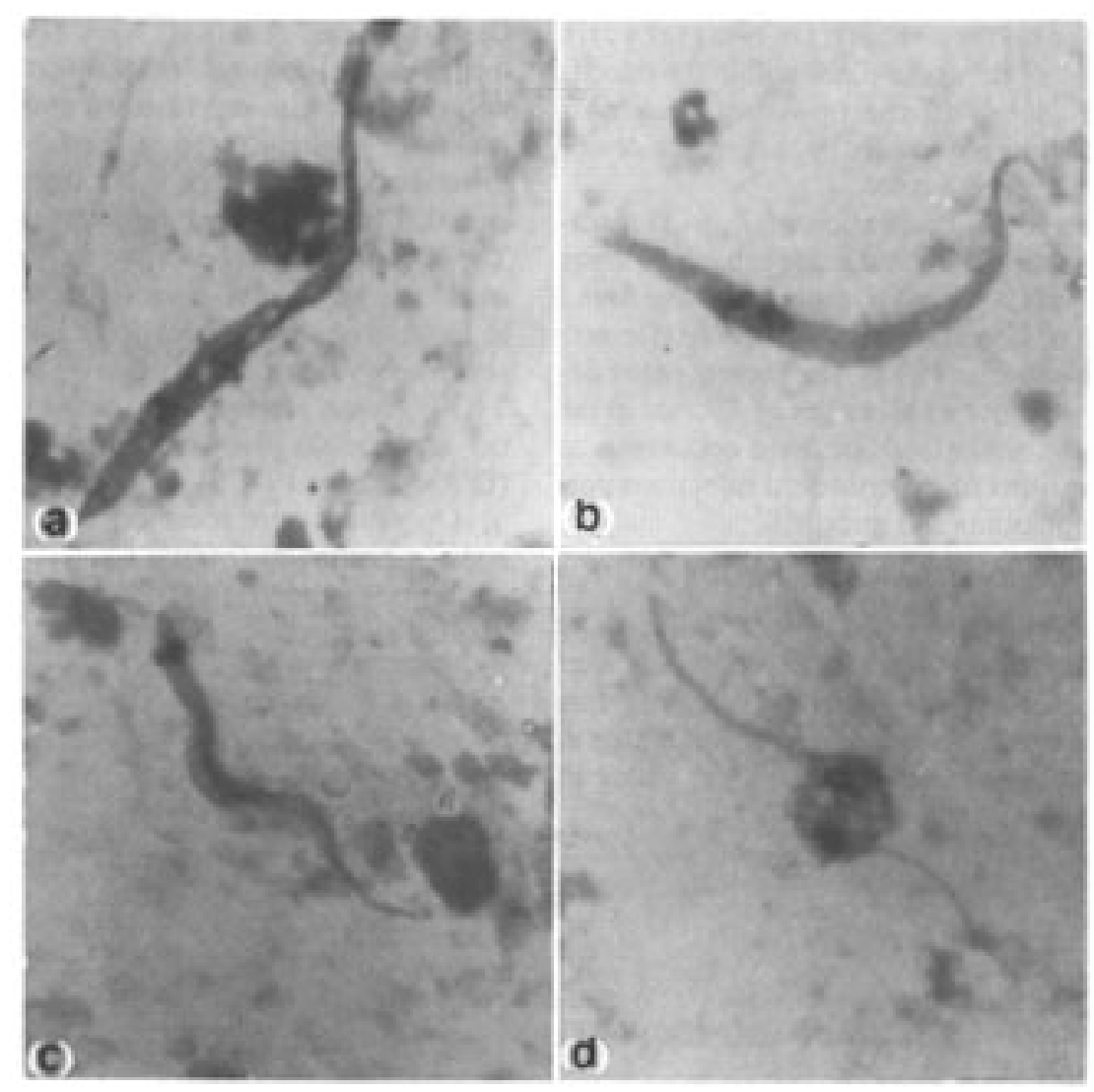

Fig. 1: content of anal glands of opossums naturally infected with Trypanosoma cruzi, showing epimastigote (a), procyclic (b), metacyclic (c) trypomastigotes, sphaeromastigote in division (d). (Giemsa stain, $1000 \mathrm{X}$ ). 


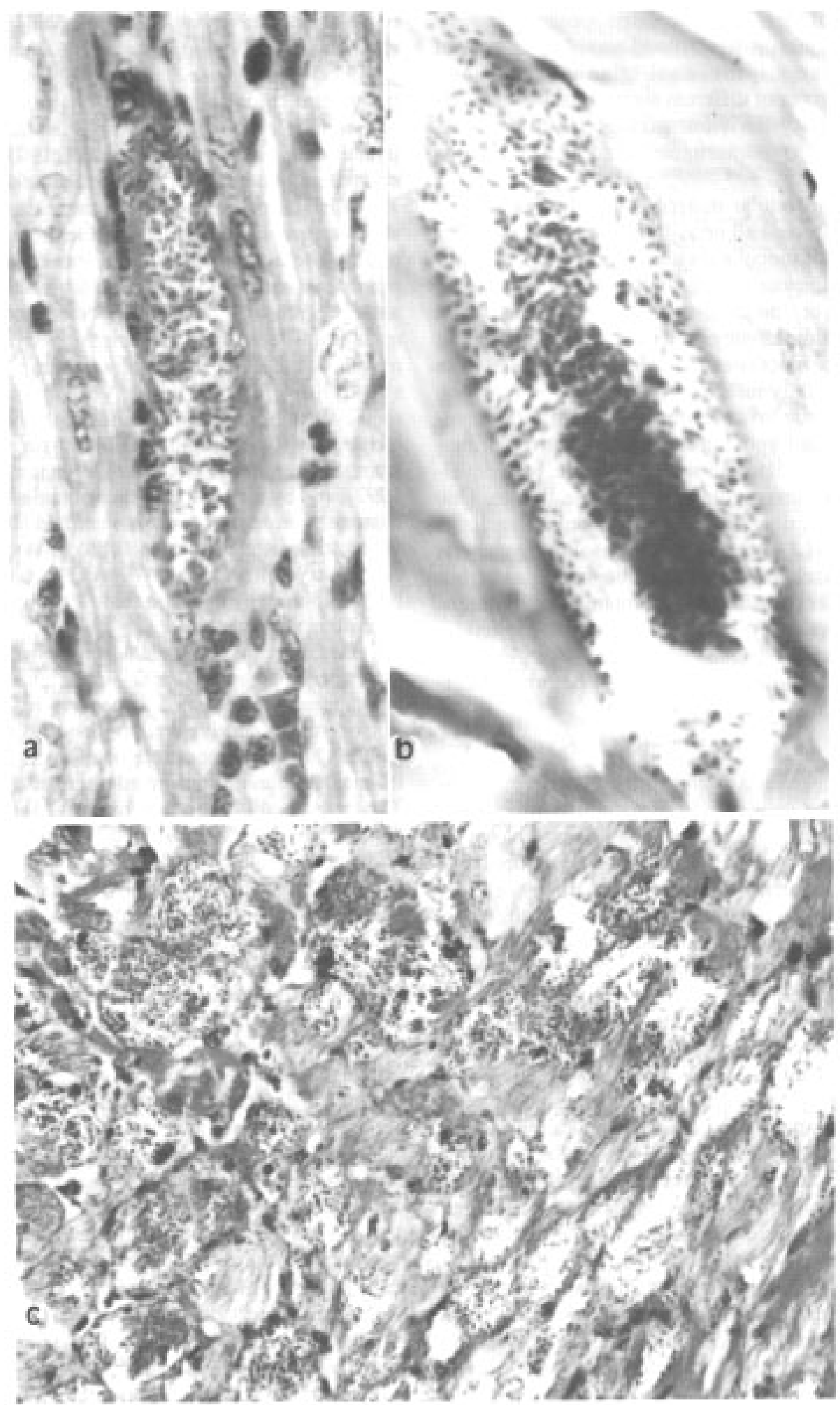

Fig. 2: tissue sections showing pseudocysts containing amastigotes. (Hematoxilin-eosin). (a): heart of opossum infected orally by glandular material cultured in LIT medium (400 X; (b): muscle layer of anal gland of opossum, infected as above (1000 X); (c) : heart of mouse infected intraperitoneally by glandular material from naturally infected opossum (400 X). 
Two of the naturally infected opossums showed trypanosomes in fresh blood samples. In both of them, one of the anal glands had many epimastigotes of different sizes; most were undergoing binary division, giving rise to rosettes, metacyclic trypomastigotes, and aberrant forms (Fig. 1).

Both glandular material and cultures derived from it infected all opossums and mice, whatever the route of inoculation used; both produced parasitism in the anal glands of opossums inoculated i/ p, orally, or into the eye. No opossum died, while all mice did, showing high parasitemias, including those mice inoculated with glandular material from experimentally infected opossums.

The tissue invasion observed in all experimentally infected opossums and mice ocurred primarily in the cardiac and skeletal muscle, with development of amastigote nests in these tissues. One opossum, orally infected with glandular flagellates cultured in LIT, showed numerous amastigote nests in the muscle layer of one of the anal glands, but had neither parasites in the lumen, nor cellular infiltration (Fig. 2).

The adult opossum inoculated with glandular material became parasitemic just before its accidental death.

\section{DISCUSSION}

The flagellates found in the odoriferous contents of the anal glands of naturally infected $D$. marsupialis can be identified as T.cruzi, based on their morphology and behavior. Thus, experimental inoculations of opossums and mice with this material produced intense infections, with intracellular parasitism and parasitemia with pleomorphic stages. Nymphs of $R$. prolixus fed on both hosts showed infective metacyclics in the feces.

Isolates of $T$. cruzi from opossum blood generally show low virulence in experimental infections (Bice \& Zeledon 1970, Barr et al. 1991, Herrera \& Urdaneta-Morales 1992). In contrast, metacyclics from glandular material, or from cultures derived therefrom, killed all 25 experimental mice, whatever the route of inoculation. Also, the same inocula colonized the anal glands of experimental opossums, whose content, in turn, proved to be highly infective when applied to the integument or mucosa. This may be epidemiologically significant, since the opossums were captured in areas densely populated by humans with rather marginal hygiene (Herrera \& Urdaneta-Morales 1992). The survival of all opossums indicates the superior adaptation of the marsupial to the parasite.

Natural colonization of the odoriferous glands has been reported in D. marsupialis and $D$. albiventris from sylvatic environments in Brazil and Venezuela (Steindel et al. 1986, Fernandes et al. 1989, Gonzalez \& Barazarte 1992), while experimental colonization of the anal glands of $D$. marsupialis and Lutreolina crassicaudata by s/c injection of bug urine (Jansen et al. 1991) and fecal material (Lenzi et al. 1984b, Steindel \& Pinto 1988) has also been reported; these experiments showed invasion of striped muscle. In our experiments, metacyclics from the lumen produced pseudocysts in the heart and skeletal muscle of mice and opossums, while those harvested from culture and administered orally also parasitized the striped muscle of the anal gland of an opossum. These results show the marked myotropism of the metacyclics from the anal glands of the opossums, a characteristic shared by the blood-stream forms from these animals (Herrera \& Urdaneta-Morales 1992), and by the fecal parasites obtained from the triatomine Panstrongylus geniculatus (SampsonWard \& Urdaneta-Morales 1988); this species of bug, always infected with $T$. cruzi, is continually being captured by us in the same area in which the opossums were captured.

D. marsupialis is abundant from eastern Mexico to northern Argentina (Perez-Hernandez 1989); in the same areas T. cruzi prevalence may reach $100 \%$. The opossums survive well in the most highly urbanized areas of Venezuela (Telford et al. 1981, Pifano 1986) and often invade human dwellings. This marsupial is a primary reservoir for Chagas' disease in the valley of Caracas (Herrera \& Urdaneta-Morales 1992).

Since three opossum species can harbor T. cruzi in the anal glands, producing metacyclics, they could be a potential source of human infection, without the need for an insect vector. The violent ejection of the anal gland content, performed in territorial marking or in response to threat, could aesily contaminate skin, mucosa, or food with infective metacyclics. This may well explain the cases of Chagas' disease from non-endemic areas where peridomestic triatomines have not been found, but where peridomestic opossums are common (references in Deane et al. 1986).

The close anatomical relationship between the anal glands, the rectum, and the urogenital organs may explain the presence of metacyclics in the urine and feces of opossums (Lenzi et al. 1984a, b, Steindel \& Pinto 1988).

The ecology of the parasite in the microhabitat of the anal glands of opossums, compared with the ecology of the parasite in the microhabitat of the triatomine intestine (Schaub 1988, references in Garcia \& Azambuja 1991) deserves study. It may be that other animals, endorsed with similar organs, 
that are susceptible to T. cruzi, and are peridomestic in endemic areas (Pietrokovski et al. 1991) could play a role in transmission of the disease.

\section{ACKNOWLEDGEMENTS}

To Mr Ian McLure for technical assistance, aid in the preparation of the manuscript, and for the English translation.

\section{REFERENCES}

Barr SC, Brown CC, Dennis VA, Klei TR 1991. The lesions and prevalence of Trypanosoma cruzi in opossums and armadillos from Southern Louisiana. J Parasitol 77: 624-627.

Barretto MP 1979. Epidemiologia, p. 89-151. In Z Brener, Z Andrade (eds). Trypanosoma cruzi e Doença de Chagas. Rio de Janeiro, Guanabara Koogan.

Bice DE, Zeledon R 1970. Comparison of strains of Trypanosoma cruzi (Chagas, 1909). J Parasitol 56: 663-670.

Brener Z 1962. Therapeutic activity and criterion of cure on mice experimentally infected with Trypanosoma cruzi. Rev Inst Med Trop São Paulo 4: 389-396.

D“Alessandro A 1976. Biology of Trypanosoma (Herpetosoma) rangeli Tejera, 1920, p. 328-403. In WHR Lumsden, DA Evans (eds). Biology of the Kinetoplastida. Vol. 1, Academic Press, New York.

Deane MP, Lenzi HL, Jansen AM 1986. Double development cycle of Trypanosoma cruzi in the opossum. Parasitol Today 2: 146-147.

Fernandes AJ, Diotaiuti L, Dias JC, Romaña AJ, Chiari E 1989. Infecção natural das glândulas anais de gambás (Didelphis albiventris) pelo Trypanosoma cruzi no município de Bambuí, MG. Mem Inst Oswaldo Cruz 84: 87-93.

Garcia ES, Azambuja P 1991. Development and interactions of Trypanosoma cruzi within the insect vector. Parasitol Today 7 : 240-244.

Gonzalez R, Barazarte R 1992. Presencia de Trypanosoma cruzi en las glándulas anales de Didelphis marsupialis naturalmente infectados en el Estado Trujillo, Venezuela. Acta Cient Venez 43 (Suppl. 1): 193.

Herrera L, Urdaneta-Morales S 1992. Didelphis marsupialis: a primary reservoir of Trypanosoma cruzi in urban areas of Caracas, Venezuela. Ann Trop Med Parasit 86: 607-612.

Jansen AM, Leon L, Machado GM, da Silva AM, SouzaLeão S, Deane MP 1991. Trypanosoma cruzi in the opossum Didelphis marsupialis: Parasitological and serological follow-up of the acute infection. Exp Parasitol 73: 249-259.
Lenzi HL, Jansen AM, Deane MP 1984a. New habitat of Trypanosoma cruzi in the vertebrate host, p. 46. XI Reunião Anual Pesquisa Básica em Doença de Chagas. Caxambu.

Lenzi HL, Jansen AM, Deane MP 1984b. The recent discovery of what might be a primordial escape mechanism for Trypanosoma cruzi. Mem Inst Oswaldo Cruz 79: 13-18.

Perez-Hernandez R 1989. Distribution of the family Didelphidae (Mammalia-Marsupialia) in Venezuela, p. 363-410. In K Redford, J Eisenberg (eds). Advances in Neotropical Mammalogy. The Sandhill Crane Press, Inc., Gainsville, FL, USA.

Pietrokovsky SM, Schweigmann NJ, Riarte A, Alberti A, Conti O, Montoya S, Wisnivesky-Colli C 1991. The skunk Conepatus chinga as New Host of Trypanosoma cruzi in Argentina. J Parasitol 77: 643-645.

Pifano F 1986. El potencial enzootico silvestre del complejo Trypanosoma cruzi - Didelphis marsupialis - Panstrongylus geniculatus y sus incursiones a la vivienda humana del valle de Caracas, Venezuela. Bol Acad Ciencias Fis Mat Nat (Caracas) 46: 9-37.

Sampson-Ward L, Urdaneta-Morales S 1988. Urban Trypanosoma cruzi: biological characterization of isolates from Panstrongylus geniculatus. Ann Soc belge Med Trop 68: 95-106.

Schaub GA 1988. Metacyclogenesis of Trypanosoma cruzi in the vector Triatoma infestans. Mem Inst Oswaldo Cruz 83: 563-569.

Steindel M, Pinto CJ 1988. Trypanosoma cruzi developmental cycle in the anal glands of experimentally infected Lutreolina crassicaudata (Marsupialia, Didelphidae). Mem Inst Oswaldo Cruz 83: 397.

Steindel M, Scholz AF, Toma HK, Schlemper BR 1986. Presence of Trypanosoma cruzi in the anal glands of a naturally infected opossum (Didelphis marsupialis) in the state of Santa Catarina, Brazil. Mem Inst Oswaldo Cruz 83: 135-137.

Telford SR, Tonn RJ, Gonzalez JJ, Betancourt P 1981. Dinamica de las infecciones tripanosomicas entre la comunidad de los bosques tropicales secos de los llanos altos de Venezuela. Bol Dir Malariol San Amb XXI: 196-209.

Urdaneta-Morales S 1983. Pleomorphism in Trypomastigotes of Trypanosoma cruzi from Blood and Cell Culture. Tropenmed Parasit 34: 225-228.

World Health Organization 1986. Report of a meeting on the feasibility of analytical epidemiological studies on Chagas' disease: guidelines for a standard protocol. Geneva. 
